\title{
Abstracts for 2013
}

\author{
Bruno Ramalho de Carvalho로 \\ ${ }^{1}$ GENESIS - Center for Assistance in Human Reproduction, Brasília, DF, Brazil \\ 2 Fertility - Assisted Fertilization Center, São Paulo, SP, Brazil
}

Trying the coordination of the committee of abstracts in an event in the size of the XVII Brazilian Congress on Assisted Reproduction will always be an undeniable opportunity for learning and knowledge exchange.

The committee this year has been committed to make our event even more special. By working to maintain the quality of previous years, no longer presented innovations, from the rules for abstracts submission to the evaluation criteria for the award. Therefore, the committee counted on the expertise and interdisciplinarity of the evaluators Amanda Souza Setti, Edilberto de Araújo Filho, Fábio Firmbach Pasqualotto, Marco Antônio Barreto Melo, Maria do Carmo Borges de Souza, Paulo Franco Taitson, Bruno Ramalho de Carvalho and Daniela Paes de Almeida Ferreira Braga.

Directions for submission contemplated standards adopted in international events and became more stringent with the aim to correct problems identified in past events. It became clear, for example, the rejection of papers that had already been published in scientific journals at the time of registration, as well as those already presented at scientific meetings in the country.

Entries in 2013 necessarily had to be classified as original studies, meta-analyzes or series and case reports, and only the first group could compete for the prize. With this initiative, we intended to enhance and stimulate research in assisted reproduction held in Brazil, without, however, fail to give due prominence to the meta-analyzes, which, when well conducted, bring important contribution to knowledge in their daily application. We received a total of 127 abstracts, 20 more compared to 2012 , of which 108 were original research, 15 were case reports or case series and 4 were meta-analyzes.

Does the work contribute to knowledge innovation? Does the title make the content clear? Are methods appropriate? Does the authors present results clearly? Are conclu- sions consistent with the objectives and results? Those questions were answered by members of the evaluation committee for the allocation of points. Thus, 110 abstracts were accepted and 17 were refused.

The sixteen highly scored abstracts will compete for prizes, which will only be announced at the closing ceremony of the congress, after computing the scores for the presentations in plenary, which this year will be decisive to choose the three studies to win the prizes.

It is worth noting that most of the abstracts strictly obeyed directions, which greatly facilitated the work of the evaluators. Among the most common misconceptions, the introductory notes and discussions appeared yet entered in the fields for the objectives and the conclusions, respectively. Unfortunately, the institutional identification along the text, which was clearly forbidden in the directions, prevented some works to compete for prizes, comprising trustworthiness and transparency of the assessment.

At the end of our Congress our work will finish, but new ideas will raise thinking at the event in 2014, when a new committee will certainly rely on this report and any other considerations, always with the intention of keeping our Congress in the deserved prominent position, since it combines, for 4 days, experts from the largest country in Latin America, where the vast majority of centers composing the Red Latinoamericana de Reproducción Asistida are set.

Finally, we know that a scientific journal survives and gains strength by publishing original articles. We confirm thus an invitation to authors to submit their complete work in form of article to our journal JBRA - Assisted Reproduction, basing their contribution to the development of Brazilian reproductive medicine and its exposure to the eyes of the world.
Recebido em 21-03-2013

Aceito em 22-07-2013
Copyright - Todos os direitos reservados a

SBRA - Sociedade Brasileira de Reprodução Assistida 